Egyptian

Orthodontic Journal

\title{
EFFECT OF DIFFERENT LIGATION DESIGNS OF SELF-LIGATING ORTHODONTIC BRACKETS ON FRICTION
}

\author{
Gasser S. Galal ${ }^{1}$, Tamer M. Bedair ${ }^{2}$, Ahmed A. Ramadan ${ }^{3}$ \\ ABSTRACT: \\ The purpose of this study was to investigate the effect of \\ three different ligation designs of self-ligating orthodontic bracket \\ systems (SLBS) on friction, under wet and dry conditions. \\ Universal testing machine was used to slide forty brackets of four \\ different bracket types (twenty passive self-ligating brackets \\ PSLBS, ten active self-ligating brackets $\mathcal{A} S \mathcal{L} B$, and ten \\ preadjusted brackets with conventional elastomeric O-ties) along \\ $0.019 \times 0.025$ stainless steel (SS) wire segments at crosshead speed \\ $8 \mathrm{~mm} / \mathrm{min}$. Testing was done under dry and wet conditions. \\ Statistical analysis of collected data revealed that all three tested

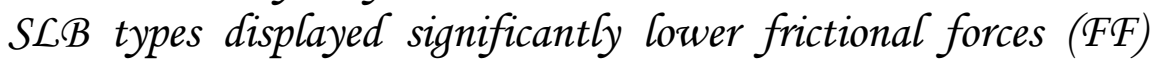 \\ than conventional brackets with conventional elastomeric O-ties \\ (CEL) under both dry and wet conditions. Both tested PSLB \\ types displayed significantly lower frictional forces than tested \\ ASLB type, under both dry and wet conditions.
}

\section{INTRODUCTION}

Fixed orthodontic appliances, like any other device, obey rules of nature and laws of physics and mechanics. Whenever there is sliding of two surfaces against each other there is a form of resistance known as friction. Among many laws governing friction, the first law of friction declares that the magnitude of the frictional resistance is proportional to

\footnotetext{
1- M.Sc. in Orthodontics, Faculty of Dentistry, Suez Canal University.

2 - Lecturer of Orthodontics, Faculty of Dentistry, Suez Canal University.

3 - Professor of Orthodontics, Faculty of Dentistry, Suez Canal University.
} 
the ligation force magnitude $(\mathrm{N})$ that is applied by the ligation method pressing the archwire against the bracket slot base multiplied by a constant which is the friction coefficient $(\mu)$ between the bracket and the archwire used. The friction coefficient $(\mu)$ is dependent on the bracket and archwire materials. ${ }^{1}$

$\mathrm{FR}=\mathrm{N} \times \mu$

While traditional ligation with elastic modules applies considerable force $(\mathrm{N})$ on wires ranging from $50-300 \mathrm{gm}^{2}$, steel ligation varies largely (0-300gm or more) and difficult to reproduce. ${ }^{3}$

Self-ligating brackets were introduced as one alternative to reduce friction with wires during orthodontic treatment. These are orthodontic bracket systems that include a mechanical device or component built into the bracket design that seals off the bracket slot without the need for steel or elastic ligature. Regardless of their design, self-ligating brackets fall into one of the following categories: passive self-ligating brackets, where the ligating component do not press against the archwire throughout the whole archwire sequence, and active self-ligating brackets, where the ligating component press on the archwire when it exceeds a certain size during the wire sequencing. ${ }^{4}$

While many researchers found that ASLBs produced significantly lower FF than conventional brackets. ${ }^{5}$ Equivalent finding were found with PSLBs. ${ }^{6-9}$ However, upon comparison between different SLB types many researchers found that PSLBs produced significantly lower FF than ASLBs. ${ }^{10-13}$ many studies comparing different bracket types found that PSLBs displayed the lowest FF followed by ASLBs, while conventional SS brackets displayed the highest FF. ${ }^{3,14-19}$

Self-ligating brackets are growing more and more popular among orthodontists in the last two decades as a low-friction alternative to bracket systems with traditional ligation and considerable friction. Many manufacturers claim that their self-ligating bracket systems reduce friction during sliding mechanics in orthodontic tooth movement. The current study was conducted to investigate the effect of three different ligation designs of self-ligating orthodontic bracket systems on friction with stainless steel archwire, under dry condition and wet condition using artificial saliva. 


\section{MATERIALS AND METHODS}

Ten Preadjusted brackets ${ }^{\mathrm{a}}$ with CEL (group A) were used as control for this study. Ten PSLBs with side clips $^{\mathrm{b}}$ (group B), ten PSLBs with rigid buccal sliding door ${ }^{\mathrm{c}}$ (group C), and ten ASLBs ${ }^{\mathrm{d}}$ with flexible labial spring (group D) were used. All selected brackets were new stainless-steel preadjusted maxillary right canine brackets, with 0.022 inch slot size, with same angulation and torque prescriptions $\left(+8^{\circ}\right.$ and $-7^{\circ}$ respectively), figure (1). Each bracket was bonded to the curved surface of a cylindrical acrylic block using alpha-cyanoacrylate adhesive. Bracket alignment was standardized while bonding using a modified instrument and $0.0215 \times 0.028$ inch wire, figure (2).
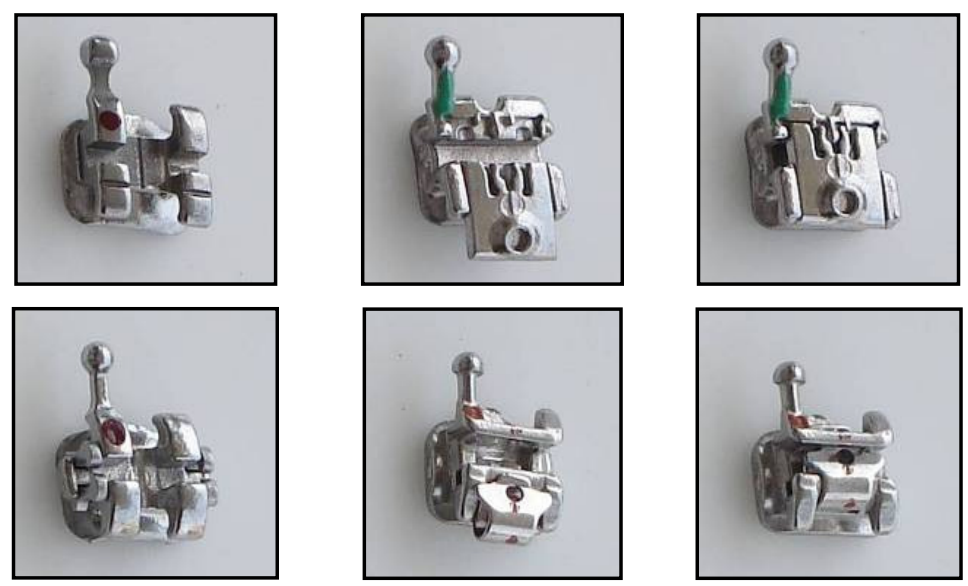

Figure (1): Gemini conventional stainless steel bracket (upper left), SmartClip self-ligating bracket with two double side clips (lower left), Carriere LX self-ligating bracket with passive buccal sliding door in opened and closed configurations (upper middle and upper right), Quick self-ligating bracket with the buccal spring in opened and closed configurations (lower middle and lower right).

a - Gemini, 3M/Unitek.

b - SmartClip, 3M/Unitek

c - Carriere LX, Ortho Organizer.

d - Quick, Forestadent.

Volume 43 - June 2013 

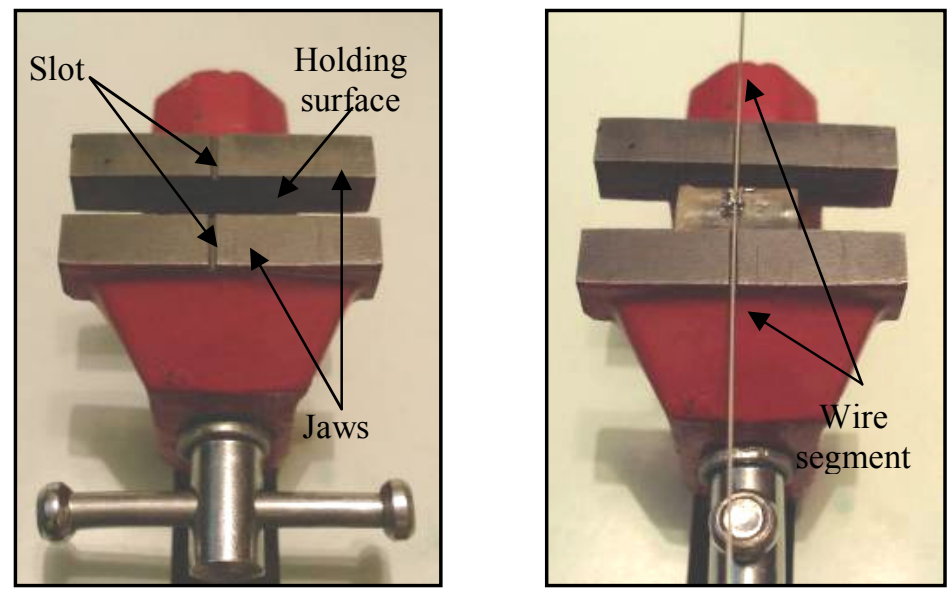

Figure (2): Modified clamp-on mini H-vice used to adjust the bracket orientation during bonding. The clamp part has two parallel jaws that are closed to hold the acrylic blocks. A slot was made in the outer surface of both jaws perpendicular to the holding surfaces, (left). $0.0215 \times 0.028$ inch straight stainless steel wire segment placed in the slots of the device and the bracket while bonding, (right).

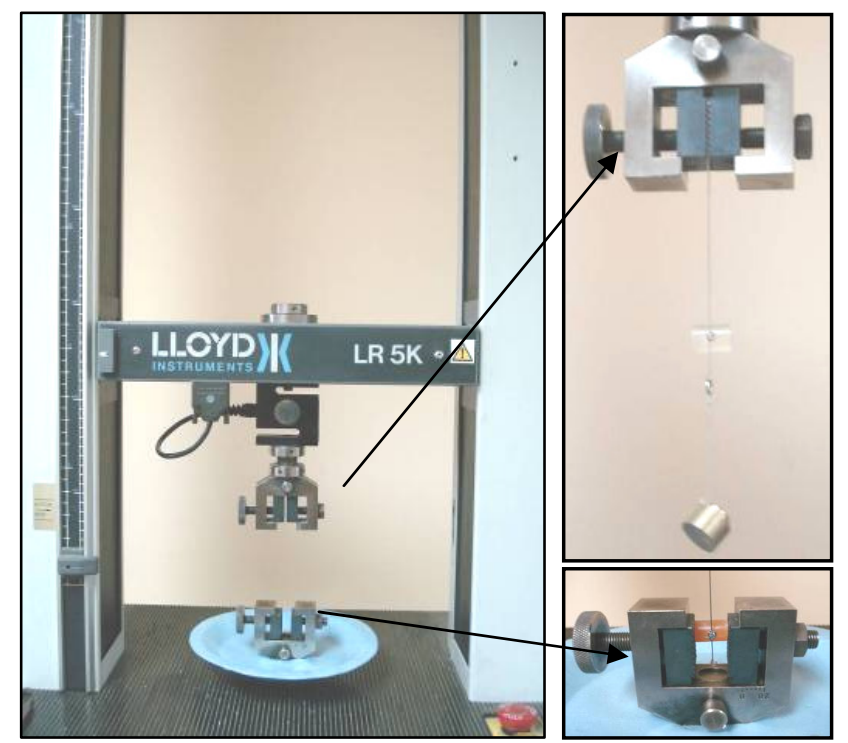

Figure (3): LR5K Lloyd universal testing machine (left), with mobile upper clamp attached to the load cell of the testing machine and a non-mobile lower clamp. Specimen held by upper clamp while the weight is hanging from the lower end (upper right). Jaws of the lower clamp tightened to hold the flat surfaces of the acrylic block (lower right). 
Each bracket was tested with one stainless-steel orthodontic wire segment with a rectangular cross-section of $0.019 \times 0.025$ inch. Control group brackets were ligated to wires using elastomeric O-ties ${ }^{\mathrm{a}}$, while self-ligating brackets were closed on wires by their ligation mechanism. Wire segments were dragged vertically from brackets by the mobile clamp of the universal testing machine ${ }^{\mathrm{b}}$ at a crosshead speed of 8 $\mathrm{mm} / \mathrm{min}^{20}$ for total time of $1 \mathrm{~min}$ and $8 \mathrm{~mm}$ distance, figure (3). The design of experimental setup was selected to allow archwires to slide through brackets parallel to bracket slot which is suitable for studying the effect of ligation mechanism and testing the effect of artificial saliva on frictional properties. ${ }^{15}$ Nexygen computer software recorded the static frictional force (SFF) as the highest initial peak on the graphic representation of each test, while the kinetic frictional force (KFF) was calculated as the mean of 100 readings after the initial peak on the graphic representation of each test, Fig (4). Each bracket was tested under dry condition then under wet condition using artificial saliva ${ }^{c}$. Testing for each bracket type was repeated ten times using a new bracket and a new archwire segment each time.

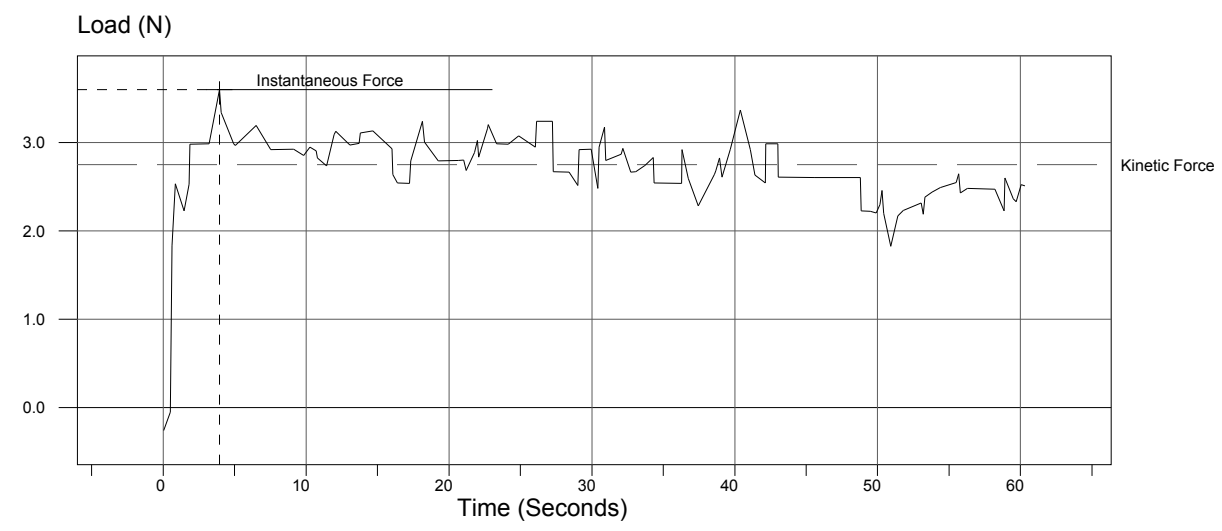

Fig (4): Graphic representation of frictional force levels.

a - Safe-T-Ties, Ortho Organizers.

b- LR5K plus, Lloyd instruments

c - Glandosane, Fresenius Medical Care Deutschland GMBH, St Wendel, Germany.

Volume 43 - June 2013 
Egyptian

Orthodontic Journal

A total of 160 readings were gathered, tabulated, statistically analyzed for descriptive statistics as well as comparative statistics. Kruskal-Wallis test was used to compare between frictional forces of the four bracket types, while Mann-Whitney $U$ test was used for pairwise group comparisons. Analysis was performed with SPSS $16.0^{\mathrm{a}}$.

\section{RESULTS}

Results in table (1) showed that the ligation design of the tested brackets had a statistically significant effect on frictional forces with all tested bracket types under dry condition. Brackets ligated with CEL group A showed the highest means for SFF and KFF $(1.659 \pm 0.775$ and $0.946 \pm 0.515)$ followed by ASLB group D $(0.486 \pm 0.168$ and $0.368 \pm 0.16)$, then PSLB group C $(0.242 \pm 0.249$ and $-0.074 \pm 0.055)$, while PSLB group $B$ showed the lowest mean SFF $(0.13 \pm 0.172$ and $-0.188 \pm 0.061)$. The differences between control group (A), ASLB group (D), and PSLB groups $(\mathrm{B} \& \mathrm{C})$ were statistically significant.

Under wet condition, Brackets ligated with CEL group A showed the highest means for SFF and KFF $(1.578 \pm 0.806$ and $1.352 \pm 0.814)$, followed by ASLB group D $(0.738 \pm 0.309$ and $0.595 \pm 0.309)$, then PSLB group $\mathrm{C}(0.163 \pm 0.079$ and $-0.168 \pm 0.149)$, and PSLB group B $(0.114 \pm 0.138$ and $-0.146 \pm 0.133)$. The difference between control group (A), ASLB group (D), and PSLB groups (B\&C) were statistically significant.

In general, there was no statistically significant difference between PSLB with side clips group (B) and PSLB with sliding door group (C).

a - SPSS, Inc., Chicago, IL, USA

Volume 43 - June 2013 
Table (1) showing the frictional forces with the four bracket groups.

\begin{tabular}{|c|c|c|c|c|c|c|c|c|c|}
\hline \multirow{3}{*}{ Condition } & \multirow{3}{*}{$\begin{array}{c}\text { Frictional } \\
\text { Force }\end{array}$} & \multicolumn{8}{|c|}{ Bracket groups } \\
\hline & & \multicolumn{2}{|c|}{$\begin{array}{l}\text { Conventional } \\
(\text { group A) (N) }\end{array}$} & \multicolumn{2}{|c|}{$\begin{array}{c}\text { PSLBs } \\
(\text { group } \mathbf{B})(\mathbf{N})\end{array}$} & \multicolumn{2}{|c|}{$\begin{array}{c}\text { PSLBs } \\
(\text { group } \mathrm{C})(\mathbf{N})\end{array}$} & \multicolumn{2}{|c|}{$\begin{array}{c}\text { ASLBs } \\
(\text { group D) (N) }\end{array}$} \\
\hline & & Mean & SD & Mean & SD & Mean & SD & Mean & SD \\
\hline \multirow{2}{*}{ Dry } & Static & $1.659^{\mathrm{a}}$ & 0.775 & $0.130^{\mathrm{d}}$ & 0.172 & $0.242^{c}$ & 0.249 & $0.486^{\mathrm{b}}$ & 0.168 \\
\hline & Kinetic & $0.946^{\mathrm{a}}$ & 0.515 & $-0.188^{c}$ & 0.061 & $-0.074^{\mathrm{c}}$ & 0.055 & $0.368^{b}$ & 0.160 \\
\hline \multirow{2}{*}{ Wet } & Static & $1.578^{\mathrm{a}}$ & 0.806 & $0.114^{\mathrm{c}}$ & 0.138 & $0.163^{c}$ & 0.079 & $0.738^{b}$ & 0.309 \\
\hline & Kinetic & $1.352^{\mathrm{a}}$ & 0.814 & $-0.146^{\mathrm{c}}$ & 0.133 & $-0.168^{c}$ & 0.149 & $0.595^{b}$ & 0.309 \\
\hline
\end{tabular}

* The force values were expressed in newtons $(\mathrm{N})$

$*$ Significant set at $\mathrm{P} \leq 0.05$

$* * *$ Means with different letters have statistically significant difference

\section{DISSCUSSION}

All selected brackets were new stainless-steel preadjusted maxillary right canine brackets, with 0.022 inch slot size, with same angulation prescription $\left(+8^{\circ}\right)$, and with same torque prescription $\left(-7^{\circ}\right)$. This was to exclude effect of these variables on testing results. One main difference between bracket groups was the ligation mechanism by which the archwires were seated into the bracket slots.

Brackets of control group (A) displayed the highest SFF and KFF. Brackets of this group were straight wire brackets ligated to wires with traditional elastomeric modules. Such elastic modules produce high seating force on the wire up to $300 \mathrm{gm}$ which is responsible for the high friction forces generated on sliding. ${ }^{2,3}$

Brackets of group (B) and (C) displayed the lowest SFF and KFF. This could be due to the fact that both were passive self-ligating brackets. The archwire was held in the slot by converting the slot into a hollow rectangular tube. This hollow tube configuration occurs in group (B) mesial to the mesial wings and distal to the distal wings of the brackets by two Nitinol clips. The hollow tube configuration occurs in group (C) 
along the whole length of the bracket slot that is covered by the buccal rigid sliding door. The archwire plays loosely in the lumen with no pressure on the archwire against the base of the bracket slot. The absence of seating force in both ligation designs explains very low readings of friction and the absence of statistically significant difference between these two PSLB types. ${ }^{14,15}$

Brackets of group (D) displayed SFF and KFF significantly lower than those of group (A) but significantly higher than those of groups (B) and $(\mathrm{C})$. Although these were self-ligating brackets but still their ligation method is a flexible spring clip pressing on the archwire. In such type the amount of seating force is related to wire size. The larger the wire size the higher the seating force. ${ }^{15}$ Never the less, the seating force is lower than that of traditional elastic modules but still higher than negligible seating force of passive ligation mechanism of PSLBs as brackets of groups (B) and (C). ${ }^{3}$

On the contrary, several other studies contradicted these findings where the SLBs did not demonstrate a statistically significant difference from conventional brackets. ${ }^{21,22}$ Even more, one study reported that SLBs generated significantly higher FF than conventional brackets with $0.019 \times 0.025$ inch stainless-steel wires. ${ }^{23}$ This conflict may be due to difference in testing apparatus which allowed rotation of the brackets relative to the archwires during testing to simulate the continuous tipping-uprighting during sliding movement of bonded teeth. In such case the sliding resistance is sum of friction and physical binding at bracket slot corners with the wire which altered the results. ${ }^{7}$ This is not the case in the current study where the experimental set up aligned the bracket slots with the archwires and did not permit tipping or rotation of the bracket which was suitable for studying the effect of ligation mechanism and testing the effect of artificial saliva on frictional properties. $^{15}$ Thus, sliding resistance was pure friction without the binding component.

In conclusion, the following was deduced:

- All three self-ligating bracket types displayed significantly lower SFF and KFF than conventional brackets with CEL under both dry and wet conditions. 
- The passive self-ligating bracket types displayed significantly lower SFF and KFF than active self-ligating bracket type under both dry and wet conditions.

- There was no significant difference in FF between the two PSLB types used in this study under dry and wet conditions.

\section{References}

1. Stannard JG, Gau LM, and Hanna MA. Comparative friction of orthodontic wires under dry and wet conditions. Am J Orthod 1986; 89:485-491.

2. Nanda R, Ghosh J. Biomechanical considerations in sliding mechanics. Biomechanics in Clinical Orthodontics. Philadelphia, WB Saunders, 1997:188-217.

3. Smith DV, Rossouw PE, and Watson P. Quantified simulation of canine retaction: Evaluation of frictional resistance. Semin Orthod 2003; 9:262-280.

4. Berger JL. The influence of the SPEED bracket's self-ligating design on force levels in tooth movement: A comparative in vitro study. Am J Orthod Dentofacial Orthop 1990; 97:219-228.

5. Hain M, Dhopatkar A, and Rock P. The effect of ligation method on friction in sliding mechanics. Am J Orthod Dentofacial Orthop 2003; 123:416-422.

6. Raouf A. Frictional force in the interactive edgewise bracket system. An in-vitro study. Master thesis, Orthodontic Department, Faculty of Oral and Dental Medicine, Cairo University, 2000.

7. Thorstenson GA and Kusy RP. Resistance to sliding of self-ligating brackets versus conventional SS twin brackets with second-order angulation in the dry and wet (saliva) states. Am J Orthod Dentofacial Orthop 2001; 120:361-370.

8. Franchi L, Baccetti T, Camporesi M, and Barbato E. Forces released during sliding mechanics with passive self-ligating brackets or nonconventional elastomeric ligatures. Am J Orthod Dentofacial Orthop 2008; 133:87-90. 
9. Gandini P, Orsi L, Bertoncini C, Massironi S, and Franchi L In Vitro Frictional Forces Generated by Three Different Ligation Methods. Angle Orthod 2008; 78:917-921.

10. Thorstenson GA and Kusy RP. Effect of archwire size and material on the resistance to sliding of self-ligating brackets with secondorder angulation in the dry state. Am J Orthod Dentofacial Orthop 2002; 122:295-305.

11. Thorstenson GA and Kusy RP. Comparison of resistance to sliding between different self-ligating brackets with second-order angulation in the dry and saliva states. Am J Orthod Dentofacial Orthop 2002; 121:472-482.

12. Budd S, Daskalogiannakis $\mathrm{J}$, and Tompson BD. A study of the frictional characteristics of four commercially available self-ligating bracket systems. Eur J Orthod 2008; 30:645-653.

13. Stefanos S, Secchi AG, Coby G, Tanna N, and Mante FK. Friction between various self-ligating brackets and archwire couples during sliding mechanics. Am J Orthod Dentofacial Orthop 2010; 138:463-467.

14. Taylor NG and Ison K. Frictional resistance between orthodontic brackets and Archwires in the buccal segments. Angle Orthod 1996; $66: 215-222$.

15. Pizzoni L, Ravnholt G, and Melsen B. Frictional forces related to self-ligating brackets. Eur J Orthod 1998; 20:283-291.

16. Hain m, Dhopatkar A, and Rock P. A comparison of different ligation methods on friction. Am J Orthod Dentofacial Orthop 2006; 130:666-670.

17. Hemade AR. A comparative study of stainless steel archwire frictional resistance between self-ligated and conventional brackets. Master thesis, Orthodontic Department, Faculty of Oral and Dental Medicine, Cairo University, Egypt, 2007.

18. Chung M, Nikolai RJ, Kim KB, and Oliver DR. Third-order torque and self-ligating orthodontic bracket-type effects on sliding friction. Angle Orthod 2009; 79:551-557. 
19. Abdel Menium MH. Variables affecting dynamic friction during sliding orthodontic tooth movement. Master thesis, Orthodontic Department, Faculty of Dental Medicine, Al-Azhar University (girls' branch), Egypt, 2009.

20. Ireland AJ, Sherriff M, and McDonald F. Effect of bracket and wire composition on frictional forces. Eur J Orthod 1991; 13:322-328.

21. Bednar JR, Gruendeman GW, and Sandrik JL. A comparative study of frictional forces between orthodontic brackets and archwires. Am J Orthod Dentofacial Orthop 1991; 100:513-522.

22. Loftus BP, Årtun J, Nicholls JI, Alonzo TA, and Stoner JA. Evaluation of friction during sliding tooth movement in various bracket-archwire combinations. Am J Orthod Dentofacial Orthop 1999; 116:336-345.

23. Reicheneder CA, GedrangeT, Berrisch S, Proff P, Baumert U, Faltermeier A, and Muessig D. Conventionally ligated verses self-ligating metal brackets - a comparative study. Eur J Orthod 2008; 30:654-660. 